\title{
Single oral dose study of two isosorbide-based aspirin prodrugs in the dog
}

\author{
John F. Gilmer, Michael A. Murphy, Jean A. Shannon, Colm G. Breen, Sheila A. Ryder and John M. Clancy
}

School of Pharmacy and Pharmaceutical Sciences, Trinity College Dublin, Dublin 2, Ireland

E-mail: gimerjf@tcd.ie

Note: This is the pre-peer-reviewed version of the following article:

Gilmer JF, Murphy MA, Shannon JA, Breen CG, Ryder SA, Clancy JM. Single oral dose study of two isosorbide-based

aspirin prodrugs in the dog. J Pharm Pharmacol. 2003 Oct; 55(10):1351-7

which has been published in final form on the publisher's website. Direct links to the definitive publisher-authenticated

version:

http://onlinelibrary.wiley.com/doi/10.1211/0022357022007/abstract

http://dx.doi.org/10.1211/0022357022007

\begin{abstract}
The objective of this study was to compare two aspirin prodrugs, isosorbide diaspirinate (ISDA) and a nitroaspirin (ISMNA), with aspirin in terms of effects on dog platelet function after administration of a single oral dose. Groups of six dogs were administered ISDA $\left(2 \mathrm{mg} \mathrm{kg}^{-1}\right)$, ISMNA $\left(4 \mathrm{mg} \mathrm{kg}^{-1}\right)$ or aspirin $\left(2 \mathrm{mg} \mathrm{kg}^{-1}\right)$. Blood was sampled at 1, 2, 4, 8, 12 and $24 \mathrm{~h}$ postdosing and evaluated for capacity to generate post-clotting thromboxane $(T X) B_{2}$. The aggregation response to arachidonic acid (AA) $(100 \mu \mathrm{M}), \operatorname{ADP}(30 \mu \mathrm{M})$ or collagen $\left(10 \mu \mathrm{g} \mathrm{mL} \mathrm{L}^{-1}\right)$ was estimated at each time-point using the whole blood impedance method. Plasma ISMN following oral administration of ISMNA was also measured and compared with plasma ISMN following administration of a physical mixture of ISMN and aspirin. ISDA administration $\left(2 \mathrm{mg} \mathrm{kg}^{-1}\right)$ was associated with a significant reduction $(P<0.05)$ in serum $\mathrm{TXB}_{2}$ at 12 and $24 \mathrm{~h}(>90 \%)$ post-dosing and persistent inhibition of $A A-$ induced platelet aggregation. ISDA administration caused a more marked depression of post-clotting $\mathrm{TXB}_{2}$ levels than aspirin in this study, although its ability to inhibit platelet aggregation was less consistent than that of aspirin. The nitroaspirin ISMNA was least effective at inhibiting platelet aggregation response or $\mathrm{TXB}_{2}$ production. The ISMN AUC $0-24 \mathrm{~h}$ for the ISMNA-treated dogs was $77 \%$ of that for the physical mix-treated dogs and the $t_{\max }$ was delayed. This study indicates that the two aspirin esters cause aspirin-like effects on platelet function, probably through aspirin release, when administered orally to dogs.
\end{abstract}

\section{Introduction}

Aspirin is effective in the treatment and prevention of a variety of cardiovascular and cerebrovascular diseases (Patrono 1994). Regular aspirin use is also associated with a significant reduction in the risk of certain types of cancer (Giovannucci 1999; Gardiner \& Gilmer 2003). Other findings point to a possible inverse relationship between aspirin and risk of Alzheimer's disease and other forms of dementia (Zandi et al. 2002). However, aspirin use carries a significantly increased risk of gastrointestinal (GI) bleeding, which is evident at doses as low as $10 \mathrm{mg}^{-1}$ day $^{-1}$ (Kurata \& Abbey 1990; Cryer et al. 1995). This effect appears to be due to a complex interplay of factors that are not fully understood. However, local suppression of cyclooxygenase (COX)-1-dependent gastro-protective functions and topical toxicity due to ion trapping are recognised as especially important contributors to aspirin toxicity (Rainsford 1989; Hawkey 1996). Pharmaceutical strategies, such as buffering or enteric coating, do not significantly reduce the risk of side effects (Kelly et al. 1996).

One potentially useful approach to this problem lies in the design of aspirin prodrugs that liberate aspirin after absorption from the Gl tract (Jones 1985). There are several reasons to expect that such compounds would have significantly diminished gastric toxicity. Esterification, by masking the carboxylic acid group, would obviate the topical irritancy component of aspirin GI toxicity, which is associated with the aspirin carboxylic acid group. Moreover, the prodrug form would not possess intrinsic COX-1 inhibitory properties, and would therefore not inhibit COX-1 until hydrolysis postabsorption. This hypothesis has not been properly tested with a true aspirin prodrug. However, available NSAID ester prodrugs generally possess lower gastric toxicity than their parent compounds (Tammara et al. 1994; Mahfouz et al. 1999; Bonina et al. 2002).

Another reason for the interest in aspirin prodrugs is that esters of aspirin generally exhibit higher aqueous stability than aspirin itself (Nielsen \& Bungaard 1989) because esterification masks the carboxylate, which performs an autocatalytic role in aspirin hydrolysis (St Pierre \& Jencks 1968). Several reports concerning the design of aspirin prodrugs are directed at forms of the drug that are suitable for percutaneous absorption due to their higher stability and lipophilicity (e.g. Lofttson et al. 1981). 
A parallel mutual prodrug strategy involves the design of nitro-aspirins in which aspirin is linked via an ester to a nitric oxide donor (Minuz et al. 1998; Del Soldato et al. 1999). Nitric oxide possesses gastro-protective properties through its ability to promote mucosal blood flow and suppress leucocyte adhesion. The prototype compound in this class, NCX-4016, exhibits greater gastric tolerability than aspirin in several animal models (Takeuchi et al. 1998; Tashima et al. 2000). NCX-4016 is now in phase II clinical trials (http://www.nicox.com/pages/keyprods.htm/\#ncx4016).

A major obstacle to the development of aspirin prodrugs has been that aspirin esters undergo hydrolysis to salicylate esters in blood, and ultimately salicylic acid, rather than aspirin (Nielsen \& Bungaard 1989). Aspirin ester prodrugs, therefore, can be more appropriately described as salicylic acid prodrugs. We have recently reported two aspirin derivatives of isosorbide that markedly depart from this general pattern because of an unusually rapid and specific butyrylcholinesterase [EC 3.1.1.8] mediated hydrolysis. One of these, ISMNA (Figure 1), the aspirin ester of isosorbide mononitrate (ISMN), is exclusively hydrolysed to aspirin in rabbit plasma and is a more potent inhibitor of platelet aggregation to arachidonic acid (AA) in rabbit platelet-rich plasma (PRP) than aspirin (Gilmer et al. 2001). The diaspirinate analogue of ISMNA, isosorbide diaspirinate (ISDA), which lacks a nitrate group, is an unusually efficient aspirin prodrug in human plasma (Gilmer et al. 2002).<smiles>CC(=O)Oc1ccccc1C(=O)O</smiles>

1

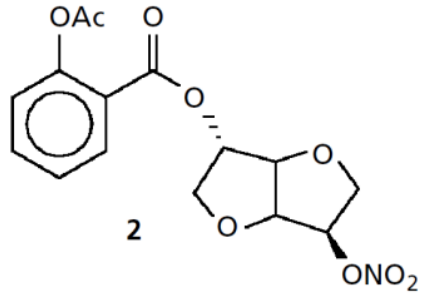

2

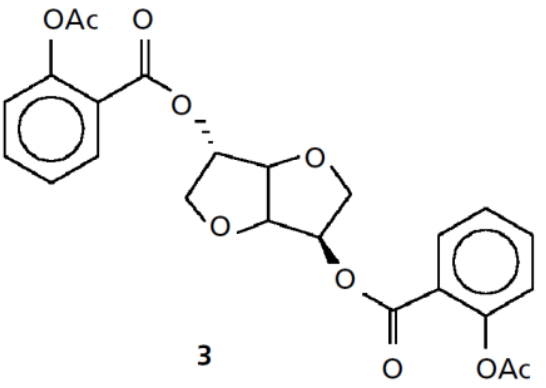

Figure 1 Chemical structures of aspirin (1), ISMNA (2) and ISDA (3).

The aim of the present study was to evaluate the efficiency of these prodrugs in vivo by measuring their effect on dog platelet function relative to aspirin, following a single low oral dose (aspirin equivalent of $2 \mathrm{mg} \mathrm{kg}^{-1}$ ). The extent of absorption of ISMN following administration of ISMNA relative to an equimolar dose of ISMN was estimated by using ISMN as a plasma marker in a second group of dogs.

\section{Materials and Methods}

\section{Animal treatment}

General procedures for animal care and housing were in accordance with the Guide for the Care and Use of Laboratory Animals (Institute of Animal Resources, Commission on Life Sciences 1996) and the requirements of the Animal Welfare Act (7USC 2131, 1985). The pharmacokinetic study was performed at the Bioresources Unit, Trinity College Dublin, which is a Department of Health approved facility under the 1876 Cruelty to Animals Act as amended by Council Directive 86/609 and SI 17/1994, and it conforms to the standards required by Annex 2 of the directive. Dogs were housed individually in stainless steel cages. None of the dogs used in this study had exposure to salicylates in the previous 14 days. No adverse effects were observed during the course of the study.

\section{Anti-platelet dosing study design}

Six healthy adult beagle dogs were used in each treatment group, three male and three female. ISDA (2 mg kg $\left.{ }^{-1}\right)$, ISMNA $\left(4 \mathrm{mg} \mathrm{kg}^{-1}\right)$ and aspirin $\left(2 \mathrm{mg} \mathrm{kg}^{-1}\right)$ were administered orally by capsule. The ISDA dosage was approximately $75 \%$ of the aspirin dose on a molar basis, while the ISMNA dosage was approximately the same as the aspirin dose on a molar basis. Individual doses were based on animal weight, which was between 9.0 and $11 \mathrm{~kg}$ on the day of treatment.

\section{Ex vivo platelet aggregation samples}

Baseline blood samples were collected for aggregation analysis 1-4 weeks before dosing. One blood sample (approximately $2.5 \mathrm{~mL}$ ) per dog was collected three times within a day, at least $2 \mathrm{~h}$ apart, into sodium citrate tubes. One blood sample per dog was obtained immediately prior to dosing (time zero) and at approximately 1, 2, 4, 8, 12 and 24 h into sodium citrate tubes (approximately 3.5\%). All blood samples were stored at room temperature and aggregation analysis was performed as soon as possible after collection. Samples were also obtained for platelet count: One blood sample per dog (approximately $1 \mathrm{~mL}$ ) was collected at the first baseline time-point and at the $12 \mathrm{~h}$ and $24 \mathrm{~h}$ time-points into tubes containing EDTA for the determination of the platelet count. The platelet counts were measured on a Technicon H.1 
automated Hematology Analyser using a helium neon laser and a 1:625 dilution of whole blood with RBC diluent and RBC/Baso Sheath fluid.

\section{Thromboxane blood samples}

One blood sample per dog $(3 \mathrm{~mL})$ was collected at the baseline time-point into tubes containing no anticoagulant. On the day of the study one blood sample per dog was obtained at 0 min (immediately prior to dosing) and at approximately 1,2 , $4,8,12$ and $24 \mathrm{~h}$ post-dosing into tubes containing no anticoagulant. The tubes were placed into a bath maintained at $37^{\circ} \mathrm{C}$ and allowed to clot for $1 \mathrm{~h}$ to obtain maximal thromboxane $(\mathrm{TX}) \mathrm{B}_{2}$ formation. The samples were then removed and indometacin ( $0.1 \mathrm{mM}$ final concentration) added to deter further COX activity. The samples were centrifuged at $4^{\circ} \mathrm{C}$ and the serum separated and frozen until analysis.

$T X B_{2}$ analysis

To remove interfering components each serum sample was extracted using octadecyl (C-18) reversed-phase columns before the ELISA assay for $\mathrm{TXB}_{2}$. The extraction efficiency was measured by spiking serum samples with approximately $5000 \mathrm{cpm}$ of ${ }^{3} \mathrm{H}-\mathrm{TXB}_{2}$ (Amersham Life Sciences) before extraction and counting the extracted sample for recovery of radiolabelled TXB . All solvent was evaporated under a stream of nitrogen at $37^{\circ} \mathrm{C}$. Tubes were capped and stored at $-20^{\circ} \mathrm{C}$ until assay. Samples were assayed for $\mathrm{TXB}_{2}$ using commercial competitive ELISA kits (Neogen Co.).

\section{Aggregometry}

Whole blood aggregation (impedance method) was monitored using a ChronoLog 540CS Aggregometer. The citrated blood samples were diluted 1:1 with modified Tyrode's buffer (Grauer et al. 1992) (0.137 M NaCl, $0.0027 \mathrm{M} \mathrm{KCl,} 0.0056 \mathrm{M} \alpha-\mathrm{D}$ glucose, $0.0021 \mathrm{M} \mathrm{MgCl}_{2} .6 \mathrm{H}_{2} \mathrm{O}, 0.0018 \mathrm{M} \mathrm{CaCl}_{2}, 0.0046 \mathrm{M} \mathrm{Na}_{2} \mathrm{HPO}_{4}, 0.012 \mathrm{M} \mathrm{NaHCO}_{3}, 2 \mathrm{IU} \mathrm{mL}^{-1}$ preservative free heparin, $\mathrm{pH} 7.40$, sterile filtered). Aggregation analysis was performed within $3 \mathrm{~h}$ of sample collection. Final concentrations of $A D P$, $\mathrm{AA}$, high-dose collagen and low-dose collagen used to induce platelet aggregation were, respectively, $30 \mu \mathrm{M}, 100 \mu \mathrm{M}$, $10 \mu \mathrm{g} \mathrm{mL}^{-1}$ and $1 \mu \mathrm{g} \mathrm{mL}^{-1}$. All dogs used in the study responded to AA in the impedance experiment at baseline.

\section{Plasma ISMN study}

Two groups of two male, purpose-bred, Labrador-cross dogs (approximately $25 \mathrm{~kg}$ ) were used. Group A was treated orally with ISMNA (4 mg kg$)$ in acetone:propane-2-diol (35:65). Group B was treated orally with a physical mix of aspirin and ISMN (1:1, $\left.4 \mathrm{mg} \mathrm{kg}^{-1}\right)$ in acetone:propane-2-diol (35:65). Blood was sampled (approximately $10 \mathrm{~mL}$ ) from the jugular vein at $0,0.5,1,2,4,8,12$ and $24 \mathrm{~h}$. No food was administered before the $12 \mathrm{~h}$ sample. Each blood sample was split between two tubes, one containing EDTA and the other containing heparin. The samples were centrifuged at $4250 \mathrm{rpm}$. Plasma was aspirated off and frozen at $-80^{\circ} \mathrm{C}$ until analysis. Analysis for ISMN was performed using a fully validated gas chromatography method employing electron capture detection. A $500 \mu \mathrm{L}$ plasma aliquot was treated with $50 \mu \mathrm{L}$ of a solution of internal standard $(750 \mathrm{mg} / 100 \mathrm{~mL}$ isosorbide-2-mononitrate in methanol). Tert-butyl-methyl-ether (1 $\mathrm{mL})$ was added and the resulting mixture stirred at $10 \mathrm{rpm}$ for $10 \mathrm{~min}$ followed by centrifugation at $3400 \mathrm{~g}$ for $10 \mathrm{~min}$. A $2 \mu \mathrm{L}$ aliquot of the organic layer was injected. No significant differences were observed between blood samples anticoagulated with EDTA or heparin.

\section{Data treatment}

Platelet aggregation, platelet count and $\mathrm{TXB}_{2}$ data were analysed by repeated measures or one-way ANOVA, or by the appropriate non-parametric measures (Friedman or Kruskal-Wallis tests). Multiple comparisons that showed significance $(P<0.05)$ were evaluated using Dunnett's or Dunn's test as appropriate. Plasma ISMN AUC ${ }_{0-24} \mathrm{~h}$ values were determined using the WinNonlin pharmacokinetic software package. $C_{\max }$ and $t_{\max }$ values were obtained directly from the analytical data.

\section{Results}

\section{$T X B_{2}$ analysis}

Normalised serum $\mathrm{TXB}_{2}$ levels, calculated as a percentage of the pre-treatment mean (baseline and time zero) for individual dogs in each of the treatment groups, are presented in Figure 2. Mean serum $\mathrm{TXB}_{2}$ levels for each treatment group are presented in Figure 3. Marked intra- and inter-individual variations in $\mathrm{TXB}_{2}$ concentration were observed in samples from the pre-treatment (baseline and time zero) time-points. For example, mean pre-treatment values in the ISDA group were $1117 \pm 383 \mathrm{ng} \mathrm{mL}^{-1}$ (range 687-2490 ng mL ${ }^{-1}$ ). High intra- and inter-individual variations in canine serum and urinary TXB have been reported previously (Yamanaka et al. 1993). An increase in $\mathrm{TXB}_{2}$ production was observed in the ISDA treatment group at the $1 \mathrm{~h}$ time-point relative to the pre-treatment mean and a significant increase at the $2 \mathrm{~h}$ time-point $(P<0.05)$. This is probably due to normal biological variation; for example, there was no significant difference between the $2 \mathrm{~h}$ values and the baseline values. The mean pre-treatment (baseline and time zero) $\mathrm{TXB}_{2}$ level among all dogs in this study was $846 \pm$

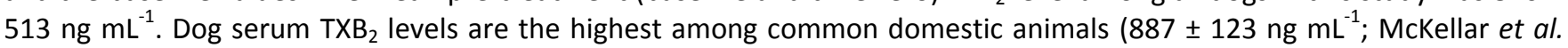


1990). ISDA administration was associated with a reduction in mean serum TXB levels at the $4,8,12$ and $24 \mathrm{~h}$ time-points and a significant decrease at the $12 \mathrm{~h}(P<0.05)$ and $24 \mathrm{~h}(P<0.01)$ time-points relative to the respective pre-treatment mean. Mean concentrations at the $12 \mathrm{~h}$ and $24 \mathrm{~h}$ time-points were $241 \pm 108$ (range: 139-426) ng mL ${ }^{-1}$ and $107 \pm 99$ (range: 29 290) $\mathrm{ng} \mathrm{mL}^{-1}$, respectively, corresponding to 21.6 and $9.6 \%$, respectively, of the pre-treatment mean in these dogs. Serum $\mathrm{TXB}_{2}$ levels in samples from three of six dogs at the $24 \mathrm{~h}$ time-point were $<5 \%$ of the pre-treatment mean and all six dogs exhibited $>80 \%$ inhibition of the respective pre-treatment mean. Mean serum TXB $_{2}$ levels at the $4 \mathrm{~h}$ and $8 \mathrm{~h}$ time-points were, respectively, $266 \pm 92$ (range: 131-376) $\mathrm{ng} \mathrm{mL}^{-1}$ and $367 \pm 117.2$ (range: 189-645) ng mL ${ }^{-1}$, corresponding to 24 and $32.8 \%$ of the pre-treatment value, respectively. Statistically significant changes in mean post-clotting $\mathrm{TXB}_{2}$ levels were not observed in the aspirin or ISMNA treatment groups. However, individual dogs in these groups exhibited $>80 \%$ inhibition of $\mathrm{TXB}_{2}$ relative to their respective pre-treatment mean at various time-points. ISMNA administration was generally associated with the least aspirin-like effect on $\mathrm{TXB}_{2}$ synthetic capacity of the three drugs tested. Platelet count was $278 \pm 69\left(\times 10^{3} \mathrm{~mL}^{-1}\right)$ at baseline, $266 \pm 50.4\left(\times 10^{3} \mathrm{~mL}^{-1}\right)$ at $12 \mathrm{~h}$ and $267 \pm 40.4\left(\times 10^{3} \mathrm{~mL}^{-1}\right)$ at $24 \mathrm{~h}$. These variations were not considered to be biologically significant.
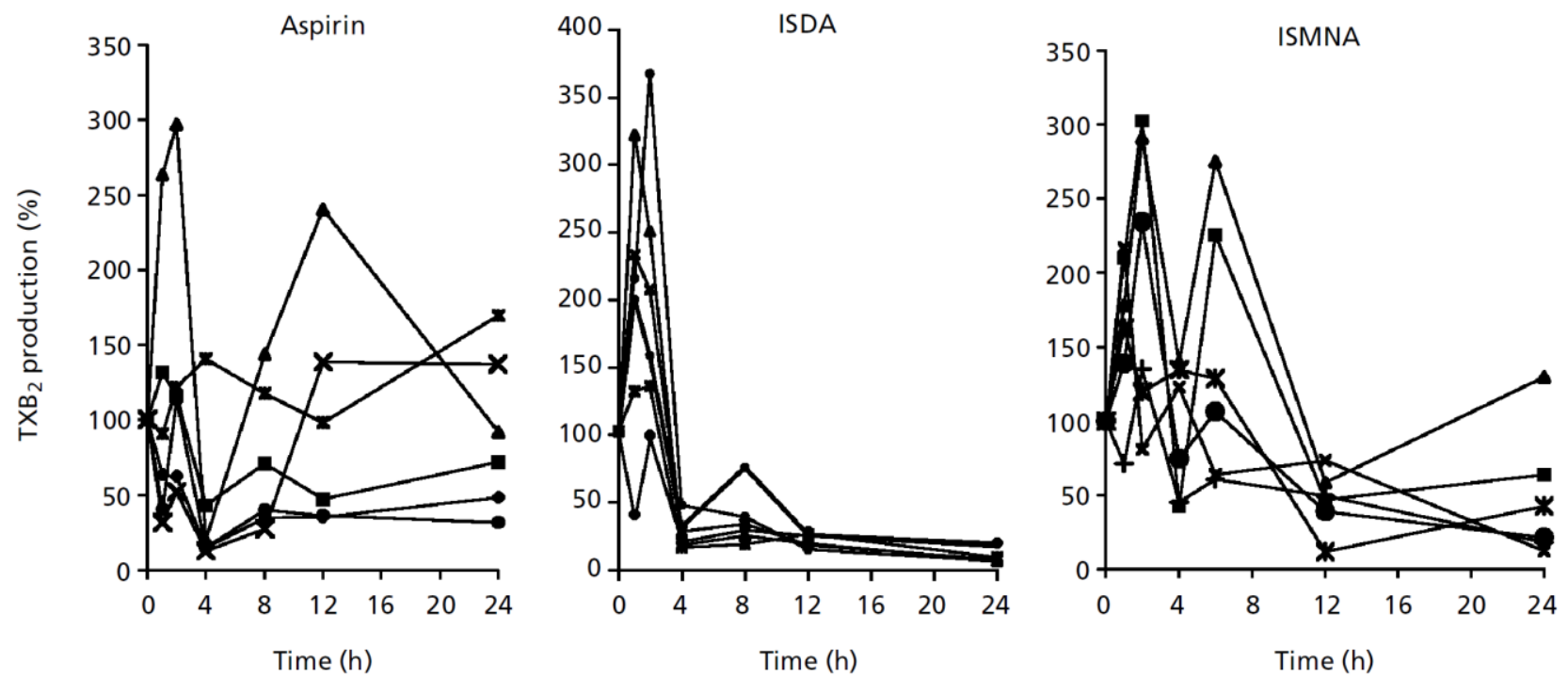

Figure 2 Plots showing exogenously produced $T X B_{2}$ levels as a percentage of the respective pre-treatment mean $T X B_{2}$ (baseline and time zero) for dogs administered aspirin (2 $\left.\mathrm{mg} \mathrm{kg}^{-1}\right)$, ISDA $\left(2 \mathrm{mg} \mathrm{kg}^{-1}\right)$ or ISMNA (4 $\left.\mathrm{mg} \mathrm{kg}^{-1}\right)$.

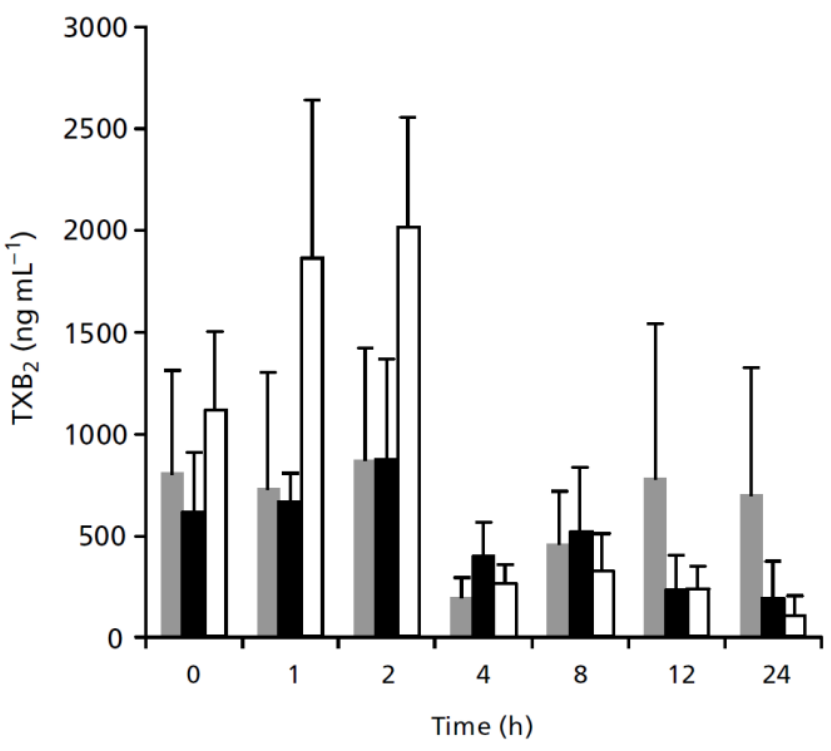

Figure 3 Mean serum $\mathrm{TX}_{2}$ levels following oral administration of aspirin ( $4 \mathrm{mg} \mathrm{kg}^{-1}$ ), ISMNA ( $4 \mathrm{mg} \mathrm{kg}^{-1}$ ) or ISDA ( $\square 2 \mathrm{mg} \mathrm{kg}^{-1}$ ) to adult beagles (s.d., $n=6)$.

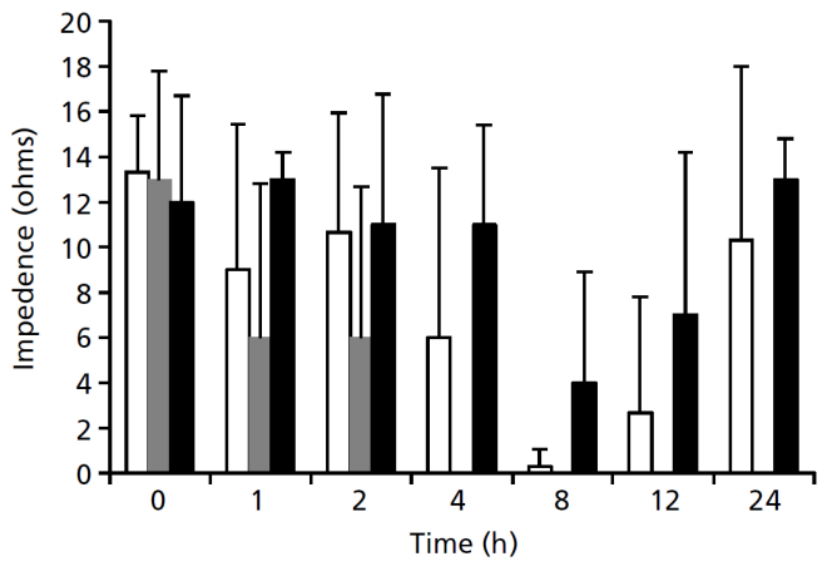

Figure 4 Mean aggregation impedance (ohms) in response to arachidonic acid for dogs administered aspirin ( $4 \mathrm{mg} \mathrm{kg}^{-1}$ ), ISMNA ( $4 \mathrm{mg} \mathrm{kg}^{-1}$ ) or ISDA ( $\square 2 \mathrm{mg} \mathrm{kg}^{-1}$ ) to adult beagles (s.d., $n=6)$. 
Aggregation in whole blood was evaluated using the impedance method of Cardinal \& Flower (1980). Mean aggregation amplitudes (ohms) in response to AA for dogs in each treatment group are presented in Figure 4. ISDA administration was associated with a significant decrease $(P<0.05)$ in mean aggregation amplitude in response to $A A$ at the $8 \mathrm{~h}$ and $12 \mathrm{~h}$ timepoints. Complete inhibition of AA-induced aggregation was observed in one, one, three, six, four and two of six dogs, respectively, at the $1,2,4,8,12$ and $24 \mathrm{~h}$ time-points. Dogs in the aspirin treatment group also exhibited consistent inhibition of aggregation response to AA. Mean aggregation amplitudes for dogs in this group were $6,6,0,0,0$ and 0 ohms at $1,2,4,8,12$ and $24 \mathrm{~h}$, respectively, whereas the pre-treatment mean was $13 \mathrm{ohms}$. Inhibition of aggregation response to AA was observed least consistently in the ISMNA treatment group. However, a statistically significant decrease in mean aggregation impedance was observed at the $8 \mathrm{~h}$ time-point with six of six dogs exhibiting complete or delayed aggregation response $(P<0.05)$. No abnormalities were observed in response to ADP $(30 \mu \mathrm{M})$ or high-dose collagen $\left(10 \mu \mathrm{g} \mathrm{mL} \mathrm{L}^{-1}\right)$ in any of the treatment groups; however, some incidence of delayed aggregation was observed in response to low-dose collagen $\left(1 \mu \mathrm{gL}^{-1}\right)$ in the ISMNA and ISDA treatment groups (Figure 5). Samples from dogs in the aspirin treatment group were stimulated with collagen $\left(1 \mu \mathrm{g} \mathrm{mL}^{-1}\right)$ at the $24 \mathrm{~h}$ time-point only. One of the samples did not aggregate; however data for the baseline response to low-dose collagen were not collected for dogs in this group. Aspirin is a weak inhibitor of collageninduced platelet aggregation in all species as collagen-initiated aggregation can bypass the AA cascade. Aspirin is also a weak inhibitor of ADP aggregation and the results for the two prodrugs are, therefore, unsurprising.

\section{Plasma ISMN results}

Mean plasma ISMN levels following administration of either ISMNA or an ISMN-aspirin physical mix are presented in Figure 6 and parameters are given in Table 1. The ISMN AUC $0-24 \mathrm{~h}$ for the ISMNA-treated dogs was $77 \%$ of that for the physical mixtreated dogs. ISMN shows complete oral bioavailability in humans (Major et al. 1984) but is reported to be somewhat less well absorbed in dogs (71.5\%; Sponer et al. 1984). The analytical data indicates a $\mathrm{t}_{\max }$ for the ISMNA treatment group of $4 \mathrm{~h}$ whereas the physical mix $t_{\max }$ was $2 \mathrm{~h}$; however, there was no significant difference between ISMN levels at the $2 \mathrm{~h}$ timepoint in the ISMNA treatment group $\left(624 \mathrm{ng} \mathrm{mL}^{-1}\right)$ and the $4 \mathrm{~h}$ time-point $\left(647 \mathrm{ng} \mathrm{mL}^{-1}\right)$.

Table 1 Pharmacokinetic parameters for ISMN in dogs $(n=2)$ administered either a 1:1 physical mixture $\left(4 \mathrm{mg} \mathrm{kg}^{-1}\right)$ of aspirin and ISMN, or ISMNA $\left(4 \mathrm{mg} \mathrm{kg}^{-1}\right)$.

\begin{tabular}{lll}
\hline Parameter & ISMNA & ISMN-aspirin mix \\
\hline $\mathrm{AUC}_{0-24 \mathrm{~h}}\left(\mathrm{ng} \mathrm{h} \mathrm{mL}^{-1}\right)$ & 5662.75 (range 5517-6140) & 7331.94 (range 6406-8850) \\
$\mathrm{C}_{\max }\left(\mathrm{ng} \mathrm{mL} \mathrm{L}^{-1}\right)$ & 647 (range 639-656) & 1175 (range 981-1370) \\
$\mathrm{t}_{\max }(\mathrm{h})$ & 4 & 2 \\
\hline
\end{tabular}

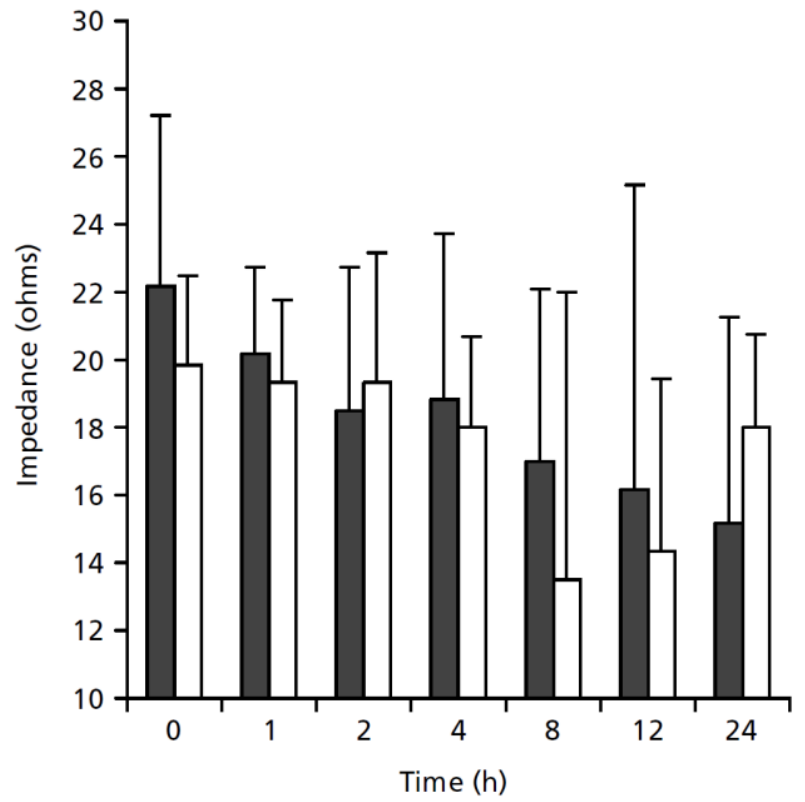

Figure 5 Mean whole blood impedance values (ohms) in response to low-level collagen (1 $\mu \mathrm{g} \mathrm{mL}^{-1}$ ) following administration of ISMNA ( $\square \mathrm{mg} \mathrm{kg}^{-1}$ ) or ISDA ( $\square 2 \mathrm{mg} \mathrm{kg}^{-1}$ ) to beagles $(n=6)$.

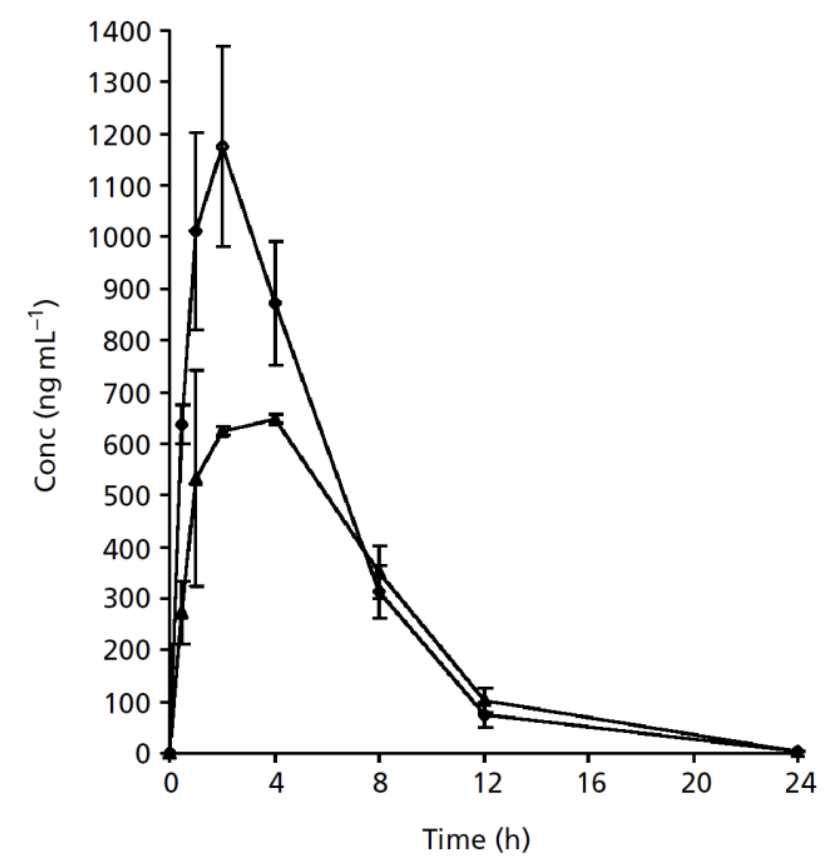

Figure 6 Mean ISMN plasma levels in dogs $(n=2)$ administered either a 1:1 physical mixture of aspirin and ISMN (-๑-) (4 mg kg-1) or ISMNA (- - -) $\left(4 \mathrm{mg} \mathrm{kg}^{-1}\right)$. The error bars mark the range of the two determinations. 


\section{Discussion}

Thromboxane $B_{2}$ is the stable hydrolase of the highly evanescent $T X A_{2}$, one of the most potent platelet aggregatory and vasoconstrictive substances known. In this study ex vivo production of $\mathrm{TXB}_{2}$ during clotting was used as a measure of functional platelet cyclooxygenase (COX-1) following oral administration of ISDA, ISMNA or aspirin. The post-clotting measurement of $\mathrm{TXB}_{2}$ is the most frequently used means of evaluating COX inhibitors in humans and other species (McKellar et al. 1990; Patrigiani et al. 1994; Brideau et al. 1996) mainly because this approach reduces variability due to sampling, which profoundly affects direct measurement of $\mathrm{TXA}_{2}$ and its metabolites.

Suppression of ex vivo $\mathrm{TXB}_{2}$ production was most clearly observed in the ISDA treatment group with maximal mean inhibition ( $>90 \%$ ) at the $24 \mathrm{~h}$ time-point. Inhibition of post clotting TXB $_{2}$ by ISDA at $24 \mathrm{~h}$ was greater than the maximal inhibition in the aspirin treatment group at $4 \mathrm{~h}(P<0.05)$. ISDA administration was also associated with significant inhibition of platelet aggregation response to AA. Curiously, whereas aggregation amplitude correlated with diminished serum $\mathrm{TXB}_{2}$ up to the $12 \mathrm{~h}$ time-point, thereafter these two indices of COX-1 activity diverged. Furthermore, for individual dogs in the ISDA treatment group there was no relationship between impedance response to $A A$, and post-clotting $\mathrm{TXB}_{2}$ production at the $24 \mathrm{~h}$ time-point.

In the aspirin treatment group, blockade of the aggregation response to AA was maintained up to the $24 \mathrm{~h}$ time-point (Figure 5) whereas platelet capacity to generate $\mathrm{TXA}_{2}$, as reflected in mean post-clotting $\mathrm{TXB}_{2}$, had returned to normal (Figure 3).

Canine platelets have a short circulation lifespan and the return of biochemically competent cells within $24 \mathrm{~h}$ of administration of a single low dose of aspirin is expected (Oshima et al. 1984). In contrast, it appears that recovery of platelet function follows a similar time-course to that observed in humans (Rao et al. 1981). Canine platelets exhibit complex responses to AA and its metabolites with marked inter- and intra-breed differences in platelet sensitivity to TXA . There is little correlation between the ability of individual dogs to produce thromboxane and their aggregation response to $A A$, suggesting that inter-dog variability is due to the mechanism that mediates aggregation and secretion in response to $\mathrm{TXA}_{2}$ (Johnson et al. 1979; McGoff et al. 1989). These variations are particularly apparent in the turbidometric aggregation model (Born 1962) using canine PRP (Chignard \& Varagaftig 1976). Aggregation to AA in canine whole blood is usually less variable because of potentiation of the platelet response to AA by other mediators not present in PRP (Grauer et al. 1992; Kurata et al. 1995) but highly variable responses to AA have been reported (Jüttner et al. 2000).

In this study, blood samples from all dogs at all baseline time-points responded normally to AA (10-14 ohms). In general, platelet aggregation response to AA and platelet capacity to generate TXA ${ }_{2}$ correlated at the $4 \mathrm{~h}$ and $8 \mathrm{~h}$ time-points but not at the $12 \mathrm{~h}$ or $24 \mathrm{~h}$ time-points. These observations may be reflective of a complicated and possibly dynamic relationship between platelet sensitivity to thromboxane and thromboxane levels in the dog. Nevertheless, the strong inhibitory effects of ISDA on $\mathrm{TXB}_{2}$ production as well as the general suppression of aggregatory response to $A A$ in both prodrug treatment groups indicates that aspirin release occurs in vivo following oral administration of the two prodrugs.

One can only speculate on whether release occurred before or after absorption of the two prodrugs from the gut. The susceptibility of both compounds towards plasma-mediated hydrolysis (Gilmer et al. 2001, 2002) precludes the possibility of accurate direct plasma measurement of the intact species. However, several factors suggest that both prodrugs may be absorbed intact to some extent. ISMNA is stable towards aqueous hydrolysis and in the presence of $\alpha$-chymotrypsin $\left(\mathrm{t}_{1 / 2}=87 \mathrm{~min}\right)$, a typical digestive 'esterase', but is hydrolysed rapidly and with high specificity by serum cholinesterase $\left(\mathrm{t}_{1 / 2}=2.8 \mathrm{~min}\right.$ in $10 \%$ plasma; Gilmer et al. 2001). Moreover, aqueous and $\alpha$-chymotrypsin-catalysed hydrolysis of both compounds occurs through the salicylate pathway, generating isosorbide derivatives and salicylic acid. These metabolites cannot account for the pharmacological effects of ISMNA and ISDA observed in this study. It is notable that ISMNA exhibited weaker anti-platelet effects than aspirin even though it is a more potent inhibitor of platelet aggregation in vitro. The preliminary pharmacokinetic study reported here suggests that the maximal systemic ISMN availability following ISMNA administration is delayed and less extensive than that following administration of an equimolar ISMN-aspirin mixture. Whether this is due to relatively poor absorption of ISMNA, poor dissolution or slow hydrolysis to ISMN is not clear. The lesser inhibitory effects of ISMNA on platelet function observed in this study, relative to aspirin or ISDA, appear to be due to limited absorption of the intact prodrug as aspirin release from ISMNA requires the presence of butyrylcholinesterase present principally in blood.

\section{Conclusion}

In this study two putative aspirin prodrugs were compared with aspirin as inhibitors of platelet function and platelet capacity to generate $\mathrm{TXB}_{2}$ ex vivo in the dog. All three substances showed maximal effects on platelet aggregation at the $4 \mathrm{~h}$ time-point. Whereas aspirin inhibition of platelet function persisted to the $24 \mathrm{~h}$ time-point, aggregation impedance recovered in the two prodrug treatment groups. On the other hand, ISDA treatment had the most pronounced effect on ex vivo $\mathrm{TXB}_{2}$ production, evident up to the $24 \mathrm{~h}$ time-point. The study indicates that these compounds are orally effective aspirin prodrugs. Both ISMNA and ISDA may be more suitable for percutaneuous formulation than aspirin as they possess greater aqueous stability and are more lipophilic. Our current work is directed towards further probing of the absorption and stability characteristics of the two prodrugs and evaluating their gastric toxicity profile. 


\section{References}

Bonina, F., Puglia, C., Santagati, N. A., Saija, A., Tomaino, A., Tita, B. (2002) Oligoethylene ester derivatives of ketoprofen, naproxen and diclofenac as oral prodrugs: a pharmacological evaluation. Pharmazie 57: 552-555. PMID: 12227196.

Born, G. V. R. (1962) Aggregation of blood platelets by adenosine diphosphate and its reversal. Nature 194: 927-929. PMID: 13871375. DOI: $10.1038 / 194927 \mathrm{b0}$.

Brideau, C., Kargman, S., Liu, S., Dallob, A. L., Ehrich, E. W., Rodger, I. W., Chan, C. C. (1996) A human whole blood assay for clinical evaluation of biochemical efficacy of cyclooxygenase inhibitors. Inflamm. Res. 45: 68-74. PMID: 8907587. DOI: 10.1007/BF02265118.

Cardinal, D. C., Flower, R. J. (1980) The electronic aggregometer: a novel device for assessing platelet behaviour in whole blood. J. Pharmacol. Method 3: 135-158. PMID: 7392654. DOI: 10.1016/0160-5402(80)90024-8.

Chignard, M., Varagaftig, B. (1976) Dog platelets fail to aggregate when they form aggregating substances upon stimulation with arachidonic acid. Eur. J. Pharmacol. 38: 7-18. PMID: 954835. DOI: 10.1016/0014-2999(76)90195-3.

Cryer, B., Luk, G., Feldman, M. (1995) Effects of very low doses of aspirin (ASA) on gastric, duodenal and rectal prostaglandins (PGs) \& mucosal injury. Gastroenterology 108: A77. DOI: 10.1016/0016-5085(95)22971-X.

del Soldato, P., Sorrentino, R., Pinto, A. (1999) NO-aspirins: a class of new anti-inflammatory and antithrombotic agents. Trends Pharmacol. Sci. 20: 319-323. PMID: 10431210. DOI: 10.1016/S0165-6147(99)01353-X.

Gardiner, P. S., Gilmer, J. F. (2003) The medicinal chemistry implications of the anti-cancer effects of aspirin and the NSAIDs. Mini-rev. Med. Chem. 3: 441-450. PMID: 12769697. DOI: 10.2174/1389557033488033.

Gilmer, J. F., Moriarty, L. M., McCafferty, D. F., Clancy, J. M. (2001) Synthesis, hydrolysis kinetics and antiplatelet effects of isosorbide mononitrate derivatives of aspirin. Eur. J. Pharm. Sci. 14: 221-227. PMID: 11576827. DOI: 10.1016/S0928-0987(01)00183-X.

Gilmer, J. F., Moriarty, L. M., Lally, M. N., Clancy, J. M. (2002) Isosorbide-based aspirin prodrugs: II. Hydrolysis kinetics of isosorbide diaspirinate. Eur. J. Pharm. Sci. 16: 297-304. PMID: 12208460. DOI: 10.1016/S0928-0987(02)00124-0.

Giovannucci, E. (1999) The prevention of colorectal cancer by aspirin use. Biomed Pharmacother. 53: 303-308. PMID: 10472428. DOI: 10.1016/S0753-3322(00)88500-5.

Grauer, G. F., Rose, B. F., Toolan, L. A., Thrall, M. A. H., Colgan. S. P. (1992) Effects of low dose aspirin and specific thromboxane synthetase inhibition on whole blood platelet aggregation and adenosine triphosphate secretion in healthy dogs. Am. J. Vet. Res. 53: 1631-1635. PMID: 1416368.

Hawkey, C. J. (1996) Non-steroidal anti-inflammatory drug gastropathy: causes and treatment. Scand. J. Gastroenterol. Suppl. 220: 124127. PMID: 8898449. DOI: 10.3109/00365529609094763.

Johnson, G.J., Leis, L.A., Rao, G.H., White, J.G. (1979) Arachidonate-induced platelet aggregation in the dog. Thromb. Res. 14: 147-154. PMID: 425077. DOI: 10.1016/0049-3848(79)90033-1.

Jones, G. (1985) Decreased toxicity and adverse reaction via prodrugs. In: Bundgaard H. (ed.) Design of prodrugs. Elsevier, Amsterdam, 199-241.

Jüttner, C., Rodríguez, M., Fragío, C. (2000) Optimal conditions for simultaneous measurement of platelet aggregation and ATP secretion in canine whole blood. Res. Vet. Sci. 68: 27-32. PMID: 10684755. DOI: 10.1053/rvsc.1999.0331.

Kelly, J. P., Kaufman, D. W., Jurgelon, J. M., Sheehan, J., Koff, R. S., Shapiro, S. (1996) Risk of aspirin-associated major uppergastrointestinal bleeding with enteric-coated or buffered product. Lancet 348: 1413-1416. PMID: 8937281. DOI: 10.1016/S01406736(96)01254-8.

Kurata, J. H., Abbey, D. E. (1990) The effect of chronic aspirin use on duodenal and gastric ulcer hospitalisation. J. Clin. Gastroenterol. 12: 260-266. PMID: 2193980.

Kurata, M., Ishizuka, N., Matsuzawa, M., Haruta, K., Takeda, K. (1995) A comparative study of whole-blood platelet aggregation in laboratory animals: its species differences and comparison with turbidimetric method. Comp. Biochem. Physiol. 112: 359-365. PMID: 8838690. DOI: 10.1016/0742-8413(95)02032-2.

Lofttson, T., Kaminski, J. J., Bodor, N. (1981) Improved delivery through biological membranes VIII: Design, synthesis, and in vivo testing of true prodrugs of aspirin. J. Pharm. Sci. 70: 743-749. PMID: 7264918. DOI: 10.1002/jps.2600700708.

Mahfouz, N. M., Omar, F. A., Aboul-Fadl, T. (1999) Cyclic amide derivatives as potential prodrugs II: N-hydroxymethylsuccinimide / isatin esters of some NSAIDs as prodrugs with an improved therapeutic index. Eur. J. Med. Chem. 34: 551-562. PMID: 11278041. DOI: 10.1016/S0223-5234(00)80025-2.

Major, R. M., Taylor, T., Chasseaud, L. F., Darragh, A., Lambe, R. F. (1984) Isosorbide 5-mononitrate kinetics. Clin. Pharmacol. Ther. 35 653-659. PMID: 6713775. DOI: 10.1038/clpt.1984.90.

McGoff, M.A., Allen, B.T., Der, T., Sicard, G.A., Santoro, S.A. (1989) Mechanisms of vascular graft thrombosis: role of altered canine platelet sensitivity to thromboxane. Thromb. Res. 55: 695-707. PMID: 2506670. DOI: 10.1016/0049-3848(89)90300-9.

McKellar, Q. A., Nolan, A. M., Galbraith, E. A. (1990) Serum thromboxane generation by platelets in several domestic animal species. Br. J. Vet. 146: 398-404. PMID: 2224484. DOI: 10.1016/0007-1935(90)90027-Z.

Minuz, P., Lechi, C., Zuliani, V., Gaino, S., Tommasoli, R., Lechi, A. (1998) NO-aspirins: anti-thrombotic activity of derivatives of acetylsalicylic acid releasing nitric oxide. Cardio. Drug Rev. 16: 31-47. DOI: 10.1111/j.1527-3466.1998.tb00343.x.

Nielsen, N. M., Bungaard, H. (1989) Evaluation of glycolamide esters and various other esters of aspirin as true aspirin prodrugs. J. Med. Chem. 32: 727-734. PMID: 2918521. DOI: 10.1021/jm00123a040.

Oshima, T., McCluskey, E. R., Honda, A., Needleman, P. (1984) Pharmacological manipulation of canine cyclooxygenase and thromboxane synthase in vivo: Differential renal and platelet recovery rates. J. Pharmacol. Exp. Ther. 229: 598-602. PMID: 6425495. 
Patrignani, P., Panara, M. R., Greco, A., Fusco, O., Natoli, C., lacobelli, S., Cipollone, F., Ganci, A., Créminon, C., Maclouf, J., Patrono, C. (1994) Biochemical and pharmacological characterization of the cyclooxygenase activity of human prostaglandin endoperoxide synthases. J. Pharmacol. Exp. Ther. 271: 1705-1712. PMID: 7996488.

Patrono, C. (1994) Aspirin as an antiplatelet drug. N. Engl. J. Med. 330: 1287-1294. PMID: 8145785. DOI: 10.1056/NEJM199405053301808.

Rainsford, K. D. (1989) Mechanisms of gastrointestinal toxicity of non-steroidal anti-inflammatory drugs. Scand. J. Gastroenterol. Suppl. 163: 9-16. PMID: 2683030. DOI: 10.3109/00365528909091169.

Rao, G. H. R., Johnson, G. J., Reddy, R. K., White, J. G. (1981) Rapid return of cyclooxygenase active platelets in dogs after a single oral dose of aspirin. Prostaglandins 22: 761-772. PMID: 6799989. DOI: 10.1016/0090-6980(81)90215-X.

Sponer, G., Kühnle, H. F., Strein, K., Bartsch, W., Endele, R., Dietmann, K. (1984) Pharmacokinetic aspects of isosorbide-5-mononitrate in dogs. J. Pharmacol. Exp. Ther. 228: 235-239. PMID: 6694105.

St Pierre, T., Jencks, W. P. (1968) Intramolecular catalysis in the reactions of nucleophilic reagents with aspirin. J. Am. Chem. Soc. 90: 3817-3827. PMID: 5653824. DOI: 10.1021/ja01016a040.

Takeuchi, K., Ukawa, H., Konaka, A., Kitamura, M., Sugawa, Y. (1998) Effect of nitric oxide-releasing aspirin derivative on gastric functional and ulcerogenic responses in rats: comparison with plain aspirin. J. Pharmacol. Exp. Ther. 286: 115-121. PMID: 9655849.

Tammara, V. K., Narurkar, M. M., Crider, A. M., Khan, M. A. (1994) Morpholinoalkyl ester prodrugs of diclofenac: synthesis, in vitro and in vivo evaluation. J. Pharm. Sci. 83: 644-648. PMID: 8071813. DOI: 10.1002/jps.2600830510.

Tashima, K., Fujita, A., Umeda, M., Takeuchi, K. (2000) Lack of gastric toxicity of nitric oxide releasing aspirin, NCX-4016, in the stomach of diabetic rats. Life Sci. 67: 1639-1652. PMID: 10983857. DOI: 10.1016/S0024-3205(00)00746-3.

Yamanaka, S., Miura, K., Yukimura, T., Yamamoto, K. (1993) 11-Dehydro thromboxane B2: a reliable parameter of thromboxane A2 production in dogs. Prostaglandins 45: 221-228. PMID: 8484010. DOI: 10.1016/0090-6980(93)90048-C.

Zandi, P. P., Anthony, J.C., Hayden, K. M., Mehta, K., Mayer, L., Breitner, J. C. (2002) Reduced incidence of AD with NSAID but not $\mathrm{H}_{2}$ receptor antagonists: the Cache County Study. Neurology 59: 880-886. PMID: 12297571. DOI: 10.1212/WNL.59.6.880. 